УДК 621.791 .04

Ю.А. Гасило, к.т.н., доцент

П.С. Івченко, к.т.н., доцент

Дніпровський державний технічний університет, м. Кам'янське

Г.І. Камель, д.т.н., професор

О.В. Дудніков, директор коледжу

Запорізький авіаційний коледж ім. О.Г. Івченко, м. Запоріжжя

\title{
МОДЕЛЮВАННЯ СКЛАДУ ПОРОШКОВОГО ДРОТУ ДЛЯ НАПЛАВЛЕННЯ РІЖУЧИХ КРОМОК ЖИВИЛЬНИКА 3 ОПТИМАЛЬНОЮ ТВЕРДІСТЮ
}

В роботі запропоновано склад порошкового дроту для наплавлення ріжучих кромок деталей живильника з використанням багатофакторного кореляційного аналізу. Підвищити ударну в'язкість наплавленого металу можна в результаті легування його иерієм. По результатам дослідження можна зробити висновок, що найбільш ефективним та недорогим матеріалом, який можна використовувати для відновлення наплавленням ріжучих кромок деталей живильника є матеріал 50ХНМ.

Ключові слова: моделювання, порошковий дріт, наплавлення, живильник, ріжучі кромки.

The composition of a powdered wire for overlaying welding of active faces details of a feeder with use multifactorial correlation analysis is in-process offered. To raise impact strength welded metal it is possible as a result of alloying by its cerium. By results of exploration it is possible to draw a leading-out which material 50XHM the most effective and inexpensive materials which can be used for restoration to overlaying weldings active faces of details a feeder is.

Keywords: modeling, powdered wire, overlaying welding, feeder, active faces.

\section{Постановка проблеми}

У процесі експлуатації відбувається притуплення ріжучих кромок і знос сполучення ротора та корпусу роторного живильника шведської фірми “Камюр”, це пов'язано $з$ контактним зношуванням сполучних поверхонь в умовах високого тиску (стиснення) мікрооб'ємів працюючих кромок під дією зрізання деревинної тріски та інших твердих предметів (електродів, дроту, болтів, гайок та інших сторонніх предметів).

Ріжучі кромки ротора та корпусу живильника перестають виконувати свою функцію і при цьому збільшуються зазори, що призводить до появи критичних витрату лугу з живильника та дострокове зняття їх з експлуатації. Використовуючи різні матеріали при наплавленні ріжучих кромок ротора та корпусу ми можемо досягти збільшення строку служби живильників.

В умовах світової економічної кризи, використання коштовного матеріалу для наплавлення ріжучих кромок ротора та корпусу шведської фірми "Камюр" не має під собою обгрунтування тому, в подальшій роботі нами буде розглянуто відновлення за допомогою матеріалів та зроблено вибір матеріалу, який найбільше відповідає вимогам - має достатню твердість, міцність та ударну в'язкість.

\section{Формулювання мети дослідження}

Метою роботи є розробка оптимального складу порошкового дроту з забезпеченням максимальної твердості.

\section{Виклад основного матеріалу}

Система легування $\mathrm{C}-\mathrm{Cr}-\mathrm{Mo}-\mathrm{Ni}$ прийнята за основу при розробці матеріалу для наплавлення ріжучих кромок деталей живильника приведені в табл. 1.

3 метою скорочення об'єму досліджень при виборі системи легування наплавленого металу, на підставі даних з табл. 1, проведено багатофакторний кореляційний аналіз $[1,2]$.

При цьому матриця планування експерименту [3] наведена в табл. 2.

Така матриця називається дробовою реплікою від повного факторного експерименту (ПФЕ). Для їі реалізації необхідно виконати всього 8 дослідів, що складає $1 / 8$ від ПФЕ типу 26. За наслідками $1 / 8$ репліки від ПФЕ типу 26 можна визначити значущість чинників [4]. 
Таблиия 1. Хімічний склад і механічні властивості наплавленого металу

\begin{tabular}{|c|c|c|c|c|}
\hline \multicolumn{3}{|c|}{ Масова частка, \% } & \multirow{2}{*}{$\begin{array}{c}\text { Середня твердість, } \\
\text { HRC }\end{array}$} & \multirow{2}{*}{$\begin{array}{c}\text { Середня ударна в'язкість, } \\
\text { KCU МДж/м² }\end{array}$} \\
\hline $\mathrm{C}$ & $\mathrm{Cr}$ & Mo & & \\
\hline 0,37 & 1,53 & 0,61 & 49,0 & 0,20 \\
\hline 0,38 & 1,47 & 0,78 & 51,0 & 0,22 \\
\hline 0,39 & 1,40 & 0,65 & 49,0 & 0,37 \\
\hline 0,41 & 1,69 & 0,55 & 51,0 & 0,16 \\
\hline 0,41 & 1,95 & 0,64 & 53,0 & 0,09 \\
\hline 0,45 & 1,53 & 0,72 & 49,0 & 0,12 \\
\hline 0,46 & 1,45 & 0,68 & 51,0 & 0,06 \\
\hline 0,48 & 1,57 & 0,80 & 52,0 & 0,08 \\
\hline 0,55 & 1,50 & 0,89 & 51,0 & 0,07 \\
\hline 0,57 & 1,80 & 0,88 & 54,0 & 0,07 \\
\hline 0,57 & 1,69 & 0,59 & 51,0 & 0,16 \\
\hline 0,63 & 1,72 & 0,70 & 52,0 & 0,16 \\
\hline \multicolumn{5}{|c|}{ Середнє значення Xi } \\
\hline 0,4725 & \multicolumn{2}{|c|}{1,6083} & \begin{tabular}{|l|l|}
7075 &
\end{tabular} & 0,138 \\
\hline \multicolumn{5}{|c|}{ Сума $\left(\sum\right)$} \\
\hline 5,67 & \multicolumn{2}{|c|}{19,30} &, 49 & 0,166 \\
\hline
\end{tabular}

Таблиця 2. Матриця планування

\begin{tabular}{|c|c|c|c|c|c|c|c|}
\hline № & $\mathrm{X}_{1}$ & $\mathrm{x}_{2}$ & $\mathrm{X}_{3}$ & $\mathrm{x}_{4}$ & $\mathrm{X}_{5}$ & $\mathrm{X}_{6}$ & $\mathrm{Y}_{\mathrm{i}}$ \\
\hline 1 & - & - & - & + & + & - & $\mathrm{Y}_{1}$ \\
\hline 2 & + & - & - & - & - & + & $\mathrm{Y}_{2}$ \\
\hline 3 & - & + & - & - & + & + & $\mathrm{Y}_{3}$ \\
\hline 4 & + & + & - & + & - & - & $\mathrm{Y}_{4}$ \\
\hline 5 & - & - & + & + & - & + & $\mathrm{Y}_{5}$ \\
\hline 6 & + & - & + & - & + & - & $\mathrm{Y}_{6}$ \\
\hline 7 & - & + & + & - & - & - & $\mathrm{Y}_{7}$ \\
\hline 8 & + & + & + & + & + & + & $\mathrm{Y}_{8}$ \\
\hline
\end{tabular}

В даному випадку основний експеримент необхідно проводити згідно матриці планування типу $2^{\mathrm{K}}$, де $\kappa$ - число чинників що залишилися після відсіваючого експерименту.

Найбільш важливим завданням кореляційного аналізу є вивчення залежності умовних середніх Y від X. Аналізуючи природу залежності, встановлюємо характер тієї функції, яка виражає Y залежно від X. Виходячи з викладеного, необхідно визначити параметри рівнянь емпіричної регресії для твердості досліджуваного сплаву, як функції від масової частки основних легуючих елементів: вуглецю, хрому, молібдену. Вміст решти елементів в сплаві є постійним: $0,17 \% \mathrm{~V}, 0,9 \% \mathrm{Si}, 2,5 \% \mathrm{Ni}, 1,5 \% \mathrm{Mn}$.

Обчислені середні значення і середні квадратичні відхилення твердості і ударної в'язкості залежно від масової частки основних елементів і їх кодування приведені в табл. 3.

Таблиия 3. Кодування досліджуваних значень

\begin{tabular}{|c|c|c|c|}
\hline Досліджувана величина & $\mathrm{X}_{\mathrm{i}}$ & Середнє значення & $\begin{array}{l}\text { Середнє квадра- } \\
\text { тичне відхилення }\end{array}$ \\
\hline Твердість, HRC & $\mathrm{X}_{1}$ & 51.8 & 1,654 \\
\hline Ударна в'язкість, КСU МДж/м² & $\mathrm{X}_{1}^{\prime}$ & 1,38 & \\
\hline Зміст С \% & $\mathrm{X}_{2}$ & 0,47 & 0,087 \\
\hline Зміст Сr \% & $\mathrm{X}_{3}$ & 1,6 & 0,163 \\
\hline Зміст Мо \% & $\mathrm{X}_{4}$ & 0,70 & 0,1106 \\
\hline
\end{tabular}


Значення коефіцієнтів парної кореляції приведені в табл. 4.

Таблиця 4. Коефіцієнти парної кореляції

\begin{tabular}{|c|c|c|c|c|}
\hline \multicolumn{2}{|l|}{$\begin{array}{l}\text { Випадкова вели- } \\
\text { чина }\end{array}$} & \multicolumn{4}{|c|}{ Коефіцієнти кореляції } \\
\cline { 2 - 5 } & $\mathrm{X}_{1}$ & $\mathrm{X}_{2}$ & $\mathrm{X}_{3}$ & $\mathrm{X}_{4}$ \\
\hline $\mathrm{X}_{1}$ & - & 0,47 & 0,70 & 0,37 \\
\hline $\mathrm{X}_{2}$ & 0,47 & - & 0,18 & 0,38 \\
\hline $\mathrm{X}_{3}$ & 0,70 & 0,18 & - & 0,11 \\
\hline $\mathrm{X}_{4}$ & 0,37 & 0,38 & 0,11 & - \\
\hline
\end{tabular}

Значення коефіцієнтів парної кореляції приведені в табл. 5.

Таблиия 5. Коефіцієнти парної кореляції

\begin{tabular}{|c|c|c|c|c|}
\hline \multirow{2}{*}{$\begin{array}{l}\text { Випадкова вели- } \\
\text { чина }\end{array}$} & \multicolumn{4}{|c|}{ Коефіцієнти кореляції } \\
\cline { 2 - 5 } & $\mathrm{X}_{1}^{\prime}$ & $\mathrm{X}_{2}$ & $\mathrm{X}_{3}$ & $\mathrm{X}_{4}$ \\
\hline $\mathrm{X}_{1}^{\prime}$ & - & 0,54 & 0,45 & 0,29 \\
\hline $\mathrm{X}_{2}$ & 0,54 & - & 0,18 & 0,38 \\
\hline $\mathrm{X}_{3}$ & 0,45 & 0,18 & - & 0,11 \\
\hline $\mathrm{X}_{4}$ & 0,29 & 0,38 & 0,11 & - \\
\hline
\end{tabular}

На підставі [5] рівняння емпіричної регресії в натуральному масштабі залежність твердості від масової частки трьох легуючих елементів запишемо:

$$
\mathrm{HRC}=33+12[\mathrm{C}]+6[\mathrm{Cr}]+3[\mathrm{Mo}],
$$

де $\mathrm{HRC}$ - твердість; C - склад вуглецю; $\mathrm{Cr}$ - склад хрому; Мо - склад молібдену.

Обчисливши множинний коефіцієнт кореляції з урахуванням числа параметрів рівняння лінії регресії $(0,86)$, знаходимо середню квадратичну помилку визначення твердості. Вона складе $1,654 \mathrm{HRC}$.

На підставі проведених досліджень пропонується хімічний склад наплавленого металу прийняти згідно табл. 6.

Таблиия 6. Хімічний склад металу, наплавленого розробленим порошковим дротом

\begin{tabular}{|c|c|c|c|c|c|c|c|c|c|}
\hline \multicolumn{10}{|c|}{ Масова частка елементів, \% } \\
\hline \multirow{2}{*}{$\mathrm{C}$} & $\mathrm{Cr}$ & $\mathrm{Mo}$ & $\mathrm{Ce}$ & $\mathrm{Mn}$ & $\mathrm{Si}$ & $\mathrm{Ni}$ & $\mathrm{V}$ & \multicolumn{2}{|c|}{ Не більш } \\
\cline { 7 - 11 } & & & & & & & & $\mathrm{S}$ & $\mathrm{P}$ \\
\hline 0,48 & 1,5 & 0,6 & 0,06 & 1,2 & 0,8 & 2,0 & 0,15 & & \\
\hline 0,55 & 1,7 & 0,7 & 0,12 & 1,5 & 1,0 & 2,5 & 0,20 & 0,030 & 0,030 \\
\hline
\end{tabular}

Склад розробленого порошкового дроту, що забезпечує прийнятий хімічний склад наплавленого металу представлений в табл. 7.

Таблиия 7. Склад розробленого порошкового дроту

\begin{tabular}{|c|c|c|c|c|}
\hline \multicolumn{5}{|c|}{ Вміст компонентів, \% } \\
\hline Графіт & $\mathrm{Fe}-\mathrm{Mn}$ & $\mathrm{Fe}-\mathrm{Cr}$ & $\mathrm{Fe}-\mathrm{V}$ & $\mathrm{Fe}-\mathrm{Mo}$ \\
\hline 0,4 & 3,0 & 2,5 & 0,5 & 1,3 \\
\hline Нікель & $\mathrm{Al}$ & $\mathrm{Al}-\mathrm{Ce}$ & $\mathrm{Na}_{2} \mathrm{SiF}_{6}$ & $\begin{array}{c}\mathrm{Fe} \\
\text { порошок }\end{array}$ \\
\hline 2,5 & 0,4 & 1,2 & 4,0 & 14,2 \\
\hline
\end{tabular}


Примітки:

1. Зважаючи на легку окислюваність церію на повітрі ввести його в шихту порошкового дроту неможливо. Тому введений алюмо-церий-сплав $(\mathrm{Al}-40 \%+\mathrm{Ce}-60 \%)$ який крихкий та не окислюється на повітрі.

2. Кремнє-фтористий натрій введений в шихту для скріплення водню і підвищення стабільності горіння дуги.

3. Частку матеріалу до $100 \%$ доповнює оболонка пророшкового дроту.

Допустимі масові частки елементів при заданих значеннях твердості (рис. $1-3$ ).

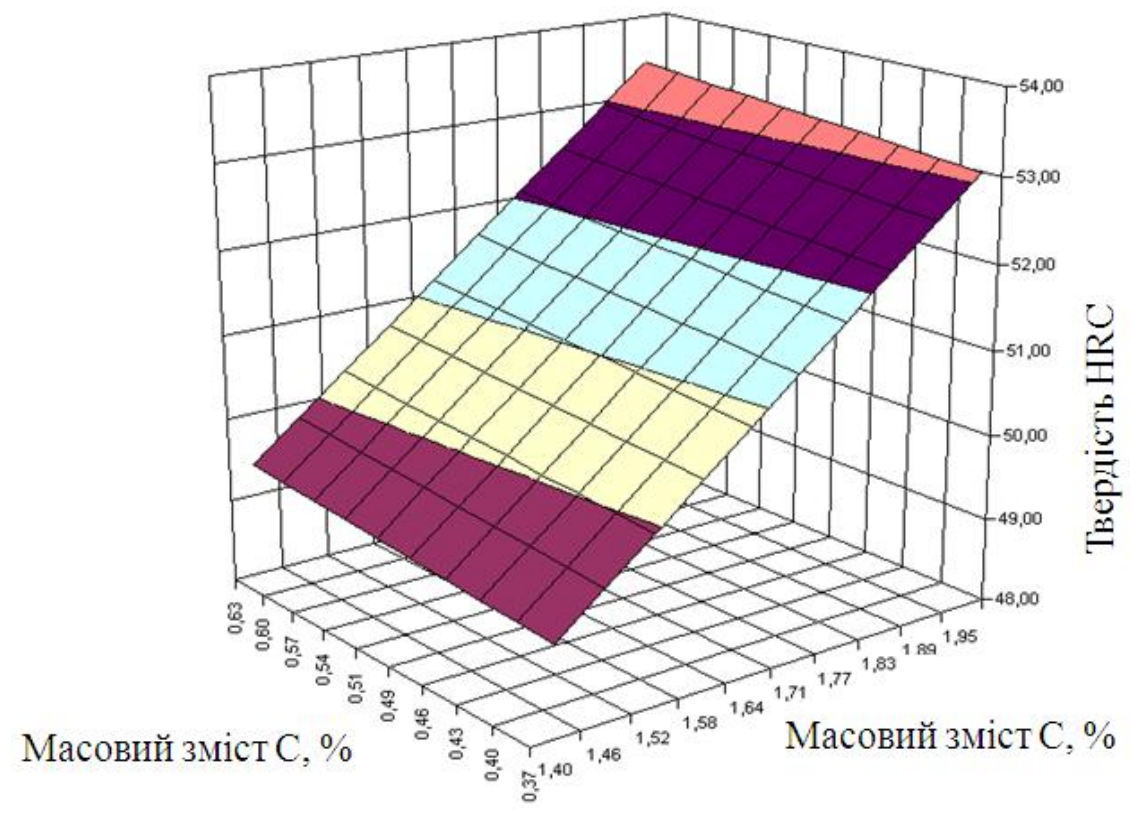

Puc. 1. Залежність твердості складу хрому та вуглецю

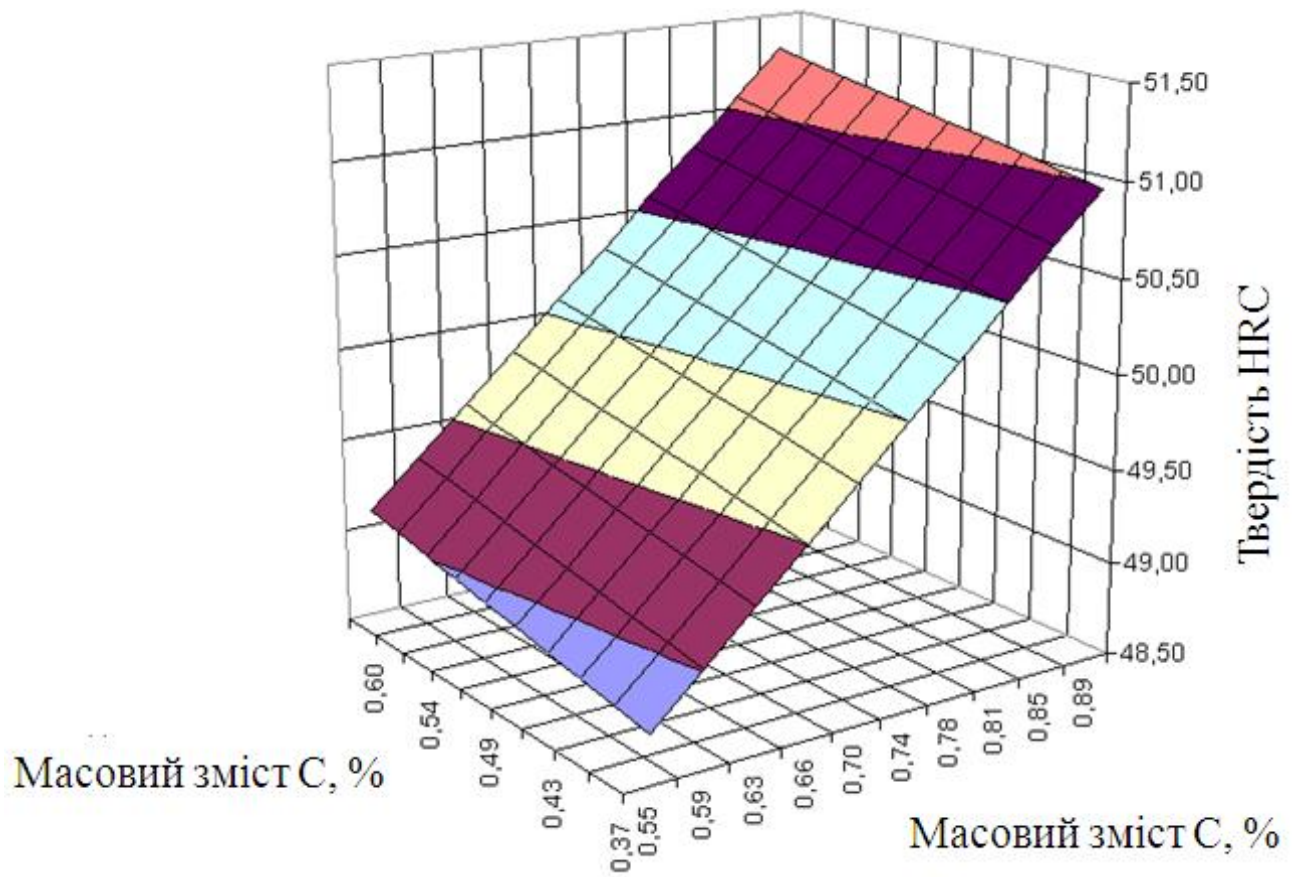

Рuc. 2. Залежність твердості складу молібдену та вуглецю 


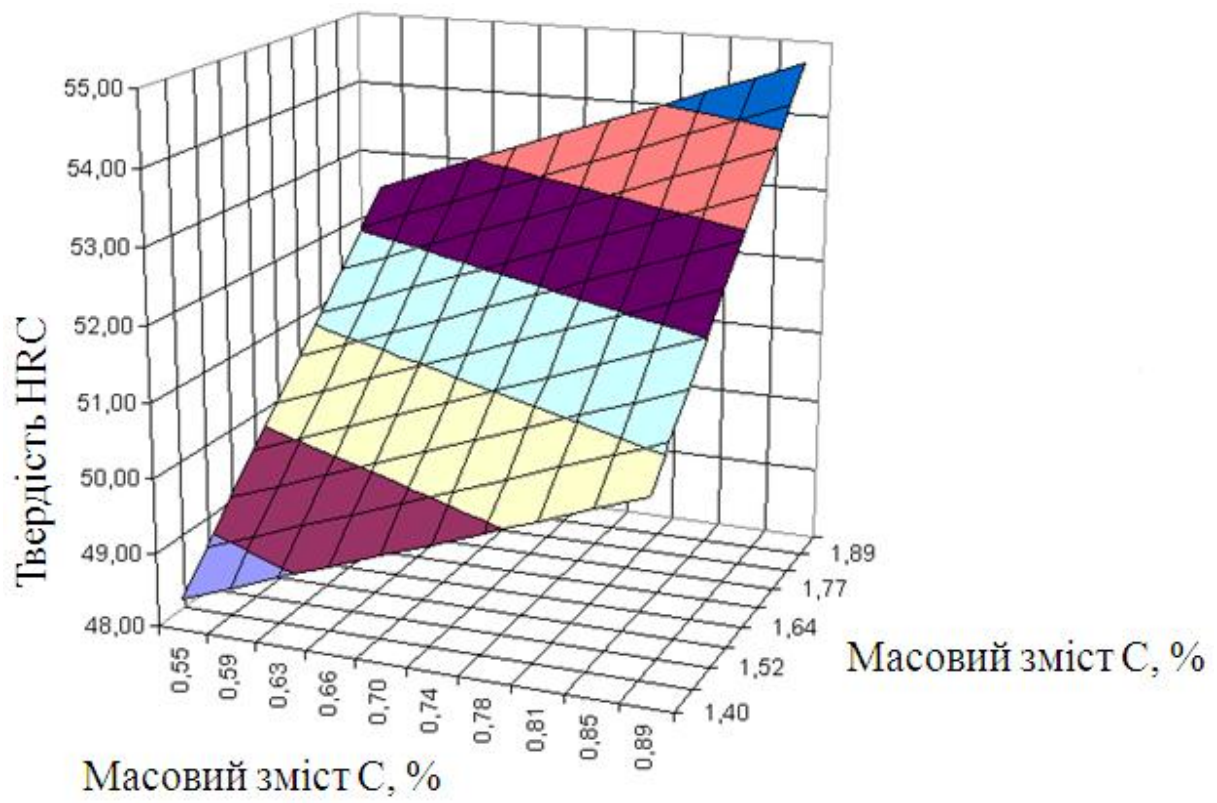

Рис. 3. Залежність твердості складу молібдену та хрому

Як показує розрахунок, легування металу повинне бути в наступних границях:

\begin{tabular}{|c|c|c|}
\hline $\mathrm{C}$ & $\mathrm{Cr}$ & Mo \\
\hline $0,48-0,55$ & $1,5-1,7$ & $0,6-0,7$ \\
\hline
\end{tabular}

Підвищити ударну в'язкість наплавленого металу можна в результаті легування його церієм. Відомо, що мікролегування стали церієм або РЗМ приводить до підвищення пластичних властивостей металу [6]. 3 метою перевірки впливу церію на ударну в'язкість були наплавлені зразки з різним його змістом. Зі збільшенням масової частки церію від $0,05 \%$ до $0,1 \%$ значення ударної в'язкості і твердості ростуть. При подальшому збільшенні змісту церію (від 0,1\% до 0,2\%) ударна в'язкість продовжує рости, але твердість помітно падає. 3 метою отримування оптимальних механічних властивостей, необхідних для матеріалу ріжучих кромок ротора та корпусу, вміст церію в наплавленому металі обмежили в межах $0,06-0,12 \%$.

Таблиия 8. Залежність твердості і ударної в'язкості наплавленого металу від масової частки церію [6]

\begin{tabular}{|c|c|c|}
\hline Масова частка церію,Се \% & $\begin{array}{c}\text { Ударна в'язкість, KCU } \\
\text { МДж/м }\end{array}$ & Твердість, НRC \\
\hline 0,005 & 0,200 & 40 \\
\hline
\end{tabular}

\section{Висновки та перспективи подальших досліджень}

По результатам дослідження можна зробити висновок, що найбільш ефективним та недорогим матеріалом, який можна використовувати для відновлення наплавленням ріжучих кромок деталей живильника $€$ матеріал 50ХНМ, який за допомогою математичного планування (багатофакторного кореляційного аналізу) було додатково леговане (збільшені вміст вуглецю,марганцю та хрому).

Було проведено дослідження фазових складових неметалевих включень, які утворюються після модифікування металу, що наплавляється церієм. Церій входить до складу оксидних складових неметалевих включень, а марганець залишається пов'язаним з сіркою. При цьому отримані неметалеві включення мають глобулярну форму, що й дозволило отримати збільшення ударної в'язкості 
Це відкриття дозволило скорегувати хімічний склад розроблюваного порошкового дроту, пояснивши необхідність додаткового модифікування церієм та збільшення відсотка марганцю в дроті.

Проведене легування дозволило отримати наплавлений метал, що відповідає заданим вимогам по твердості, міцності та ударної в'язкості, та $є$ широкодоступним для використання у промисловому виробництві.

\section{Список використаної літератури}

1. Камель Г. І. Дослідження конічних трибосистем у промисловому транспорті: монографія / Г. І. Камель, В. В. Перемітько, Р. А. Куліковський. - Дніпродзержинськ: ДДТУ, 2013. - 313 с.

2. Камель Г. І. Технологічні процеси та комплекси відновлення і зміцнення деталей: навч. посіб. / Г. І. Камель, В. М. Мілютін, П. С. Івченко, А. І. Панфілов. - Дніпродзержинськ: ДДТУ, 2015. - $496 \mathrm{c}$.

3. Адлер Ю. П. Планирование эксперимента при поиске оптимальных условий / Ю. П. Адлер. М.: Наука, 1965. - $221 \mathrm{c}$.

4. Хартман К. Планирование эксперимента в исследовании технологических процессов / К. Хартман, Э. Лицкий, В. Шетер. - М.: Мир, 1977. - 134 с.

5. Степанов И. С. Математическая статистика в технологии машиностроения / И. С. Степанов. М.: Машиностроение, $1972 .-170$ с.

6. Браун М. П. Микролегирование стали / М. П. Браун. - Киев: Наукова думка, 1982. - 304 с. 